\title{
SINGV - the Convective-Scale Numerical Weather Prediction System for Singapore
}

\author{
Xiang-Yu Huang ${ }^{1,}$, Dale Barker ${ }^{2}$, Stuart Webster ${ }^{2}$, Anurag Dipankar ${ }^{1}$, Adrian Lock $^{2}$, Marion Mittermaier ${ }^{2}$, \\ Xiangming Sun ${ }^{1}$, Rachel North ${ }^{2}$, Rob Darvell ${ }^{2}$, Douglas Boyd ${ }^{2}$, Jeff Lo ${ }^{1}$, Jianyu Liu ${ }^{1}$, Bruce Macpherson ${ }^{2}$, Peter \\ Heng ${ }^{1}$, Adam Maycock ${ }^{2}$, Laura Pitcher ${ }^{2}$, Bob Tubbs², Martin McMillan², Sijin Zhang ${ }^{1}$, Susanna Hagelin², \\ Aurore Porson ${ }^{2}$, Guiting Song ${ }^{1}$, Becky Beckett ${ }^{2}$, Wee Kiong Cheong ${ }^{1}$, Allison Semple ${ }^{2}$, and Chris Gordon ${ }^{1}$
}

${ }^{1}$ Centre for Climate Research Singapore, Meteorological Service Singapore, 36 Kim Chuan Road, Singapore 537054, Singapore

${ }^{2}$ Met Office, FitzRoy Road, Exeter, Devon EX1 3PB, United Kingdom

*Corresponding author: hans_huang@nea.gov.sg

\author{
KEYWORDS \\ Convective-scale weather \\ modelling \\ Atmospheric data \\ assimilation \\ Ensemble forecasts \\ Numerical weather \\ prediction systems \\ Deep tropics
}

\begin{abstract}
Extreme rainfall is one of the primary meteorological hazards in Singapore, as well as elsewhere in the deep tropics, and it can lead to significant local flooding. Since 2013, the Meteorological Service Singapore (MSS) and the United Kingdom Met Office (UKMO) have been collaborating to develop a convective-scale Numerical Weather Prediction (NWP) system, called SINGV. Its primary aim is to provide improved weather forecasts for Singapore and the surrounding region, with a focus on improved short-range prediction of localized heavy rainfall. This paper provides an overview of the SINGV development, the latest NWP capabilities at MSS and some key results of evaluation. The paper describes science advances relevant to the development of any km-scale NWP suitable for the deep tropics and provides some insights into the impact of local data assimilation and utility of ensemble predictions.
\end{abstract}

(c) The Author(s) 2019. This article is distributed under a Creative Commons Attribution-ShareAlike 4.0 International license.

\section{INTRODUCTION}

Unlike mid- and high-latitudes where the rainfall events are often associated with frontal systems, the heavy rains in Singapore and the surrounding Southeast Asian region are caused predominantly by thunderstorms that have a lifespan and spatial extent significantly shorter than those associated with extra-tropical frontal systems. The small scale nature of these thunderstorms makes them highly chaotic and harder to predict. Even the most sophisticated global Numerical Weather Prediction (NWP) systems in the world are known to suffer from poor (short term) forecast skill over the tropics (Žagar et al. 2013; Walters et al. 2019), which directly or indirectly is due to the dominance of localized thunderstorms in the region.

Thunderstorms are driven by convective and in-cloud processes which are parameterized in the current NWP models. In order to achieve the best performance, these models rely on tuning of the model parameters with available observations. As most of the leading NWP centers are situated in the extra-tropics, such tuning exercises are biased, for practical reasons, towards their local weather systems which makes it more challenging to use them directly over the tropics without re-tuning them against local observations (Bush et al. 2019). Data assimilation is known to improve the performance of these models by continuously adjusting the model state to the observed state. However, the current convective-scale data assimilation systems have issues when applied in the tropics due to the lack of observations and an inadequate understanding of the relevant 'balanced' states resulting from convection and cloud processes (Žagar et al. 2013; Gustafsson et al. 2018).
In recent years, ensemble prediction systems have emerged to enhance the capabilities of the existing NWP systems. These involve the production of probablistic forecasts that are appropriate to a chaotic system like the atmosphere (Molteni et al. 1996), and also include ensemble based data assimilation to improve the representation of background error-covariance (Bannister 2017). However, the development and application of these ensemble systems is very much confined to global NWP and more research is needed to evaluate its impact in high resolution regional forecast systems.

Convective-scale NWP over the tropics has always been a big challenge. There have been a few initiatives to tackle this issue both in modelling and data assimilation (Gustafsson et al. 2018), but much more still needs to be done. In these circumstances, having an NWP centre in the deep tropics like Singapore can make a big difference when it comes to understanding the limitations of the current convective-scale NWP systems. The purpose of this paper is to highlight the efforts made in this direction by the Meteorological Service Singapore (MSS) and the United Kingdom Met Office (UKMO), through a collaborative project to develop a convective-scale NWP system for Singapore (SINGV). The project, "A tropical convective-scale NWP/Nowcasting capability for Singapore," also called SINGV, started in 2013 and ended formally in 2018. The main aim of SINGV is to enable MSS to provide improved weather forecasts for Singapore and the surrounding region, with a primary focus on improved short-range prediction of localized heavy rainfall. This paper provides an overview of the SINGV development, the latest NWP capabilities at MSS and some key results of its 
evaluation, which clearly highlight the challenges of NWP in the deep tropics. A table of the acronyms used in this paper is included at the end for easy reference (see Glossary).

\section{AN ACCOUNT OF THE SINGV DEVELOPMENT}

\subsection{Year $1(2013-2014)$}

SINGV is based on the Unified Model (UM, Brown et al. 2012). The original SINGV system was based on a variable resolution configuration of the UM designed for the UK (UKV Tang et al. 2013) relocated to the Singapore region. After some initial adaption changes, the first version of SINGV (1.0) was released in 2014. Unlike the variable resolution UKV, for consistency with the Weather Research and Forecasting model (WRF, Skamarock et al. 2008) already running at MSS, the SINGV 1.0 domain centered on Singapore employed a constant $(1.5 \mathrm{~km})$ grid-spacing, nested within a larger (4.5 km grid-spacing) domain covering the Malay Peninsula and Sumatra. The latter was driven by the global UM (UM_G), which at that time had a grid resolution of 25 $\mathrm{km}$. To improve the modelling of the deep troposphere, 10 extra vertical levels were added to the original 70 UKV levels. We made a comparison between forecasts from SINGV and WRF and, based on the encouraging results, decided to continue the development of SINGV.

\subsection{Year 2 (2014-2015)}

Further experiments were conducted to assess the impact of model resolution and nesting strategy. As a result, the decision was taken to use the $1.5 \mathrm{~km}$ resolution over the larger domain for future development and testing. Further tuning of turbulence parameterization schemes was performed prior to release of SINGV 2.0. In February 2015, realtime running of a SINGV downscaler (DS), driven by UM_G, was initiated. Having gained confidence in the quality of the SINGV forecast model, initial work on SINGV Data Assimilation (SINGV-DA) also started in year 2.

\subsection{Year $3(2015-2016)$}

In the course of ongoing testing and evaluation, several model issues were identified from the real-time SINGV-DS runs, both technical and meteorological in nature. The most severe problem was in rainfall forecasts: a somewhat 'blobby' representation of deep convective cells over land manifesting as sparse, small, areas of intense convective rainfall with limited light rainfall beyond the core. In year 3 , three major developments were made to alleviate the blobbiness problem: a new 'local' moisture conservation scheme, the application of stochastic perturbations in the turbulence scheme to more easily trigger convection and an increase of turbulence mixing. Rainfall patterns produced in the subsequent SINGV 3.0 are more realistic compared to SINGV 2.0.

At the same time, the SINGV-DA capability became more fully developed with its own background error covariance and capabilities for assimilating conventional and satellite observations in the SINGV domain. In April 2016, the SINGV-DA system was implemented in real-time at MSS, with observations processed at the UKMO and lateral boundary conditions from UM_G.

\subsection{Year $4(2016-2017)$}

As the real-time SINGV-DS and SINGV-DA systems became stable and enabled routine daily evaluations, MSS forecasters were engaged in subjective evaluation studies, com- plementing objective evaluations performed by SINGV developers. The blobbiness issue was highlighted as an ongoing issue, although reduced in impact from earlier versions. One related problem was revealed from the realtime daily forecasts: the difficulty of SINGV 3.0 to forecast squall lines. Further model development and tuning was performed. The major change was the replacement of the Smith (1999) cloud scheme by the Prognostic Cloud fraction and Prognostic Condensate (PC2, Wilson et al. 2008; Morcrette 2012a,b) scheme. Combined with further tuning to the boundary layer scheme, the reduced blobbiness in rainfall and improvements in the representation of squall lines in the forecasts compared to observations were seen. A knock-on impact of these forecast improvements was a reduction in dry bias and improved (reduced) rainfall in SINGV-DA compared to SINGV-DS.

Also in year 4 , the development and real-time implementation of an initial $4.5 \mathrm{~km}$ SINGV Ensemble Prediction System (SINGV-EPS) was completed in March 2017, with an ensemble of initial conditions and lateral boundary conditions provided by the Met Office Global Regional Ensemble Prediction System (MOGREPS - Bowler et al. 2008).

\subsection{Year $5(2017-2018)$}

The UM strategy is to aim for a 'seamless' regional modelling capability suitable for all applications. A major effort was therefore made in year 5 to reduce the difference between SINGV and UKV configurations. Changes (e.g. stochastic perturbations and increase of turbulence mixing coefficient), which were helpful before but turned out to be redundant after the change in the cloud scheme, were removed and a final version (SINGV 5.0) was released at the end of the 5-year project. Although reduced, several differences between UKV and SINGV configurations remain: 1) constant grid resolution in SINGV as opposed to variable in UKV; 2) 80 vertical levels in SINGV as opposed to 70 in UKV; 3) UKV uses a diagnostic cloud scheme whereas SINGV uses a prognostic cloud scheme; 4) UKV uses stochastic boundary layer perturbations whereas they are turned off in SINGV; 5) the stability functions for convective boundary layers follow Brown (1999), with SINGV using the "conventional LEM" functions whereas the UKV uses the "standard LEM" functions ; 6) SINGV uses a free-atmospheric mixinglength that is dependent on the diagnosed turbulent layer depths, whereas for the UKV the mixing-length is fixed at $40 \mathrm{~m}$.

In order to provide consistency with the global forecast systems employed by MSS forecasters, a major effort was made in year 5 to drive SINGV-DS, SINGV-DA and SINGVEPS regional NWP configurations by European Centre for Medium-Range Weather Forecasts (ECMWF) global data, which also led to a significant improvement in regional NWP skill (see Section 4.5).

To finish the 5-year project, forecasters evaluations were conducted to assess the usefulness of SINGV in an operational environment. As a result, SINGV moved from realtime evaluation to operational application starting with the SINGV-DA configuration in 2019.

\subsection{After the project (May 2018-present)}

Since the end of the 5-year project, MSS has continued development in collaboration with the UKMO. The major achievements include the development of a DA-centered EPS system, fine tuning of parameters and enhancing the computational stability of SINGV for its operational implementation. SINGV-DA was made formally operational in 
July 2019, with similar plans for SINGV-EPS in the near future. The current operational and pre-operational configurations are presented in the following section.

\section{SINGV SYSTEM CONFIGURATION}

The original SINGV system started with a UM Variable resolution configuration for the UK, named UKV (Tang et al. 2013). Since that time, numerous aspects of the system configuration have been tested and evaluated including model domain, vertical levels, physics schemes and parameters, lateral boundary conditions, observation usages and ensemble choices. Remaining difference between the SINGV 'branch' of the regional UM configuration will be evaluated and merged in future.

\subsection{Model domain}

SINGV can run over different domains covering Singapore and surrounding areas. The most tested domain and the one used for current operations is shown in Figure 1. The highest horizontal resolution we run operationally is 1.5 $\mathrm{km}$, with $1092 \times 1026$ model points on each of 80 model levels. A zoom-in view of the domain presents the $1.5 \mathrm{~km}$ grid mesh over Singapore. The ensemble system runs over the same domain but with a lower resolution of $4.5 \mathrm{~km}, 364 \times 342$ model points and 80 model levels.

\subsection{Model dynamics and physics}

SINGV uses the UM dynamic core which employs a SemiLagrangian (SL) scheme for advection and a Semi-Implicit (SI) scheme for temporal discretization of a set of nonhydrostatic deep-atmosphere equations (Wood et al. 2014). The Arakawa C-grid for horizontal staggering and a terrainfollowing hybrid vertical coordinate with Charney-Phillips staggering is used. Mass conservation is ensured through a correcting step (Zerroukat 2010), including the correction due to mass fluxes through lateral boundaries initially through the scheme described in Aranami et al. (2015), and ultimately through the zero-lateral flux approach described in Zerroukat and Shipway (2017). Due to the stable SLSI scheme, the time step used for integrating the model forward can be large - a value of $60 \mathrm{~s}$ is chosen for the 1.5 $\mathrm{km}$ DS and DA, and 120s for the $4.5 \mathrm{~km}$ EPS integrations.

The physics schemes used in SINGV include: 1) the single moment microphysics scheme of Wilson and Ballard (1999); 2) the prognostic cloud scheme of Wilson et al. (2008); 3) the radiation scheme of Edwards and Slingo (1996); 4) the blending boundary layer scheme of Boutle et al. (2014), which blends the one-dimensional planetary boundary layer scheme of Lock et al. (2000) and the three-

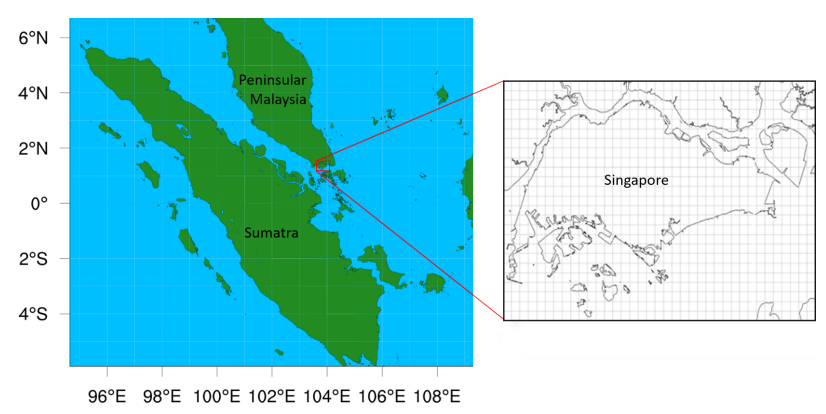

FIGURE 1. SINGV domain (left) and a zoom-in view of the domain for the Singapore showing the $1.5 \mathrm{~km}$ grid mesh (right). dimensional Smagorinsky-Lilly scheme (Lilly 1962). No convection parameterization is used in SINGV, although some early tests with the $4.5 \mathrm{~km}$ grid were performed with the convection scheme on and off. More details of the implementation of these schemes in SINGV can be found in Webster et al. (2020).

\subsection{LBC, SMC and SST}

SINGV is a limited-area system and therefore requires specified lateral boundary conditions (LBC). Originally SINGV followed the same strategy as that of UKV with the global $\mathrm{UM}(\mathrm{UM}-\mathrm{G})$ forecasts providing LBCs (and global analysis initial BCs). During the SINGV project, the option to use ECMWF forecasts as lateral boundaries has been added. This change brings a significant improvement in the SINGV precipitation forecast scores (see section 4 below). ECMWF forecasts at $00 \mathrm{Z}$ and $12 \mathrm{Z}$ now provide the default lateral boundaries for all SINGV configurations.

For lower boundaries, SINGV uses Soil Moisture Content (SMC) and Sea Surface Temperature (SST) provided by the UKMO. The SMC data are produced by the Met Office Rainfall and Evaporation Calculation System (MORECS, Hough and Jones 1997). SST data is provided by the Operational Sea Surface Temperature and Sea Ice Analysis (OSTIA, Donlon et al. 2012) system at UKMO. Both SMC and SST are kept constant throughout the forecast and are only updated once per day. In the data assimilation SMC and SST are updated daily at 09Z. Land boundary conditions are handled by the Joint UK Land Environment Simulator (JULES, Best et al. 2011).

\subsection{SINGV-DS}

The downscaler (DS) option of SINGV (SINGV-DS) uses ECMWF analyses at $00 \mathrm{Z}$ and $12 \mathrm{Z}$ as initial conditions and produces $48 \mathrm{~h}$ forecasts twice daily. Due to changes in model resolution, mainly through the model orography and model physics, especially from parameterized-convection to explicit convection, the early hours of the SINGV-DS forecast suffers from a 'spin-up' problem (similar to other DS models), leading to poor short-range (up to 9 hours) forecasts. However due to the long waiting times for the arrival of ECMWF analyses and forecasts (which means the subsequent SINGV forecasts are available in operations only about 8 hours after analysis time) the spin-up effect has only a small impact on operational forecast quality. The use of ECMWF driving model data means SINGV-DS has the advantage of using analyses/LBCs produced by the best global data assimilation system (the downside being that SINGV-DS provides no benefit for very short-range NWP).

\subsection{SINGV-DA}

To reduce the aforementioned spin-up problem and prepare for assimilating locally received high resolution observations (e.g. radar data) a data assimilation capability has been included in SINGV. The data assimilation (DA) option of SINGV (SINGV-DA, Heng et al. 2020) uses almost the same configuration as the UKV data assimilation system (Gustafsson et al. 2018). SINGV-DA can also use either 3Dimensional Variational data assimilation (3D-Var, Lorenc et al. 2000) or 4-Dimensional Variational data assimilation (4D-Var, Rawlins et al. 2007) developed in the UM system. The thoroughly tested and now operationally used option is 3D-Var with FGAT (First Guess at Appropriate Time), running with a 3-hour cycle at 00Z, 03Z, 06Z, 09Z, 12Z, 15Z, $18 \mathrm{Z}$ and 21Z. 
At each cycle the 3h SINGV model forecast from the previous cycle, which uses ECMWF forecasts as lateral boundaries, is used as the background for 3D-Var. The background error covariances are computed from SINGV forecast differences between forecasts valid at the same time but started from a different time, as done similarly for UKV and described in Ingleby (2001).

Observations collected around the analysis time, from -1.5 hour to +1.5 hour, are assimilated. Currently SINGV-DA assimilates most of conventional observations and satellite data provided to MSS via the Met Office (including GTS and local feeds to Exeter). Conventional observations include surface observations, radiosondes and aircraft reports. The satellite data include radiances, feature derived upper-air and surface winds, and pseudo-observations of cloud at the cloud top (Renshaw and Francis 2011). Variational Bias Correction (VarBC, Cameron and Bell 2015) is used to reduce the bias in the radiance observations. The UKV observation error covariances are used in SINGV. SINGV-DA is also able to assimilate radar radial velocities and radar rain-rates. However, the use of the radar data is still at the experimental stage.

SINGV-DA, like UKV, produces zero analysis increments at the lateral boundaries for scalar variables and constrains the wind vector increments normal to the boundaries to be zero. Large-scale driving conditions are therefore imposed at the lateral boundaries and so SINGV-DA does not need an additional adjustment for lateral boundaries.

After each 3D-Var, the Incremental Analysis Update scheme (IAU, Bloom et al. 1996) is applied over a 2-hour window as an initialization step prior to the launch of a $48 \mathrm{~h}$ forecast. In the operational environment, as SINGVDA does not need to wait for the latest ECMWF analyses which normally arrive MSS about 7 hours after the analysis time (00Z analyses arrive at 07Z), it starts as soon as observations for that cycle arrive (normally about 3 hours after the analysis time). Compared to SINGV-DS, SINGV-DA provides more frequent forecasts, earlier delivery, and has reduced spin-up effects.

\subsection{SINGV-EPS}

Tropical convection is an inherently chaotic process and a commonly accepted approach is to use probabilistic forecasts to provide estimates of uncertainty. These forecasts can be generated using an ensemble technique which runs the same model multiple times using perturbed initial conditions, and model perturbations (e.g. stochastic physics, different model versions or even different models). With limited area models, different lateral boundaries are often used.

The ensemble prediction system (EPS) of SINGV (SINGV-EPS) is developed from the Met Office Global and Regional Ensemble Prediction System over UK (MOGREPSUK, Hagelin et al. 2017; Porson et al. 2019). The system can be considered as an ensemble of SINGV-DS forecasts. SINGV-EPS runs over the same model domain as SINGV-DS and SINGV-DA but using a lower horizontal resolution of $4.5 \mathrm{~km}$ with $364 \times 342$ model points due to computing power constraints.

SINGV-EPS is driven by the ECMWF ensemble prediction system. All the SINGV-EPS members start from ECMWF ensemble initial conditions and use ECMWF ensemble forecasts as lateral boundaries. Although we could run a 51-member ensemble using all ECMWF ensemble forecasts, only 12 members (the control and the first 11 odd-index members) are selected for the pre-operational system due to computing power constraints. SINGV-EPS has been running twice daily at $00 \mathrm{Z}$ and $12 \mathrm{Z}$ with the preoperation status after the operational SINGV-DA.

\subsection{Verification}

Verification of SINGV has been performed both subjectively and objectively. A few intensive evaluations of the SINGV performance have been carried out by forecasters at MSS and UKMO. Initial subjective evaluation results were compared with objective verification scores in Sun et al. (2020).

The objective verification scores include bias and root mean square (RMS) differences between the model output and observations of temperature, wind and humidity. As precipitation is the main concern at MSS, several scores for precipitation are employed using rain-gauge data, radar data and satellite data as references. As a demonstration of the objective verification, we only show examples of Fractions Skill Scores (FSS - Roberts and Lean 2008) in this paper.

FSS is a neighborhood verification method which evaluates precipitation forecasts against observations using nearest neighbors to identify the scale of interest. The forecast and observed precipitation fields are binarised using a threshold. The spatial distribution of events within an area defined by the chosen scale is represented using fractions. FSS is computed as the fraction's Brier score. The scores vary from 0 (no skill) to 1 (perfect skill). Forecasts at different forecast lengths are verified against the Global Precipitation Measurement (GPM) Integrated Multi-Satellite Retrievals for GPM (IMERG) data product (Skofronick-Jackson et al. 2017). As the resolution of GPM data is lower than SINGV forecasts, the SINGV precipitation fields are averaged to the GPM IMERG resolution, $0.1^{\circ}$, before the comparisons.

\section{RESULTS}

The development of SINGV has been accompanied by parallel runs, typically over selected months. All the changes to SINGV were systematically tested and compared using the previous version as a benchmark. Before each minor and

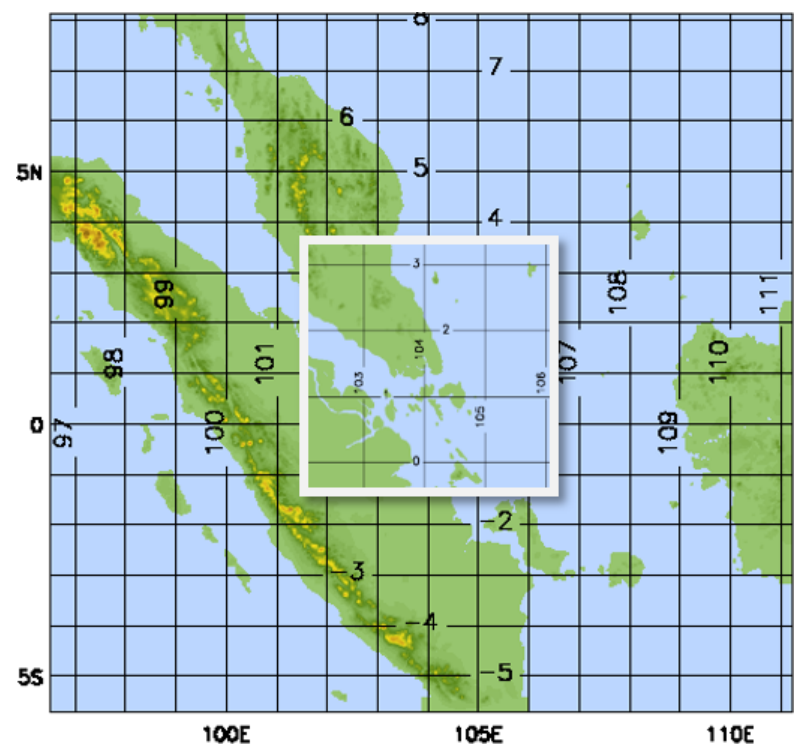

FIGURE 2. The domains used by SINGV 1.0 and WRF. The outer domain has a $4.5 \mathrm{~km}$ resolution and the inner domain has a $1.5 \mathrm{~km}$ resolution. 
major version upgrade, some earlier experiments were repeated. In this section, the most important results obtained during development of SINGV are presented.

\subsection{Early comparisons with WRF}

The WRF (Skamarock et al. 2008) model has had significant exposure to tropical convective-scale applications in Southeast Asia. A WRF configuration was used at MSS before the SINGV project started. A comparison between the UM-based SINGV and WRF was therefore of general interest to MSS and the wider NWP community in the area. During the first year of the SINGV project (2013-2014) SINGV 1.0 performance was compared with the WRF system already running at MSS. Both systems were configured using the nesting domains (Figure 2). The outer domain has $4.5 \mathrm{~km}$ resolution covering the Malay Peninsula, Sumatra and part of Borneo. The inner domain has $1.5 \mathrm{~km}$ focusing on Singapore. In this early configuration, SINGV uses UM_G analyses and forecasts as initial condition and lateral boundary conditions while WRF uses the Global Forecast System (GFS, the United States operational NWP system) analyses and forecasts. In order to separate the driving model impact, we also repeated the WRF runs using the UM-G analyses and forecasts.

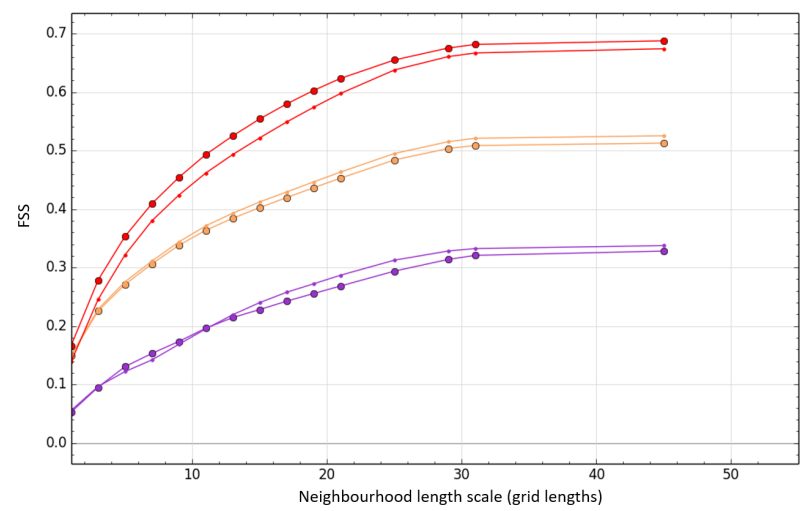

FIGURE 3. FSS with respect to GPM IMERG precipitation analyses for 24hourly accumulated precipitation threshold of $16 \mathrm{~mm}$ calculated over the $1.5 \mathrm{~km}$ domain (the small domain in Figure 2) and averaged over the period 1 to 30 June 2011, for UM-SINGV (red), UM-WRF (orange) and GFS-WRF (purple) with forecast model horizontal resolutions of $4.5 \mathrm{~km}$ (large dots) and $1.5 \mathrm{~km}$ (small dots). The neighborhood length scales are in multiples of $0.1^{\circ}$, which is the resolution of the GPM IMERG product.

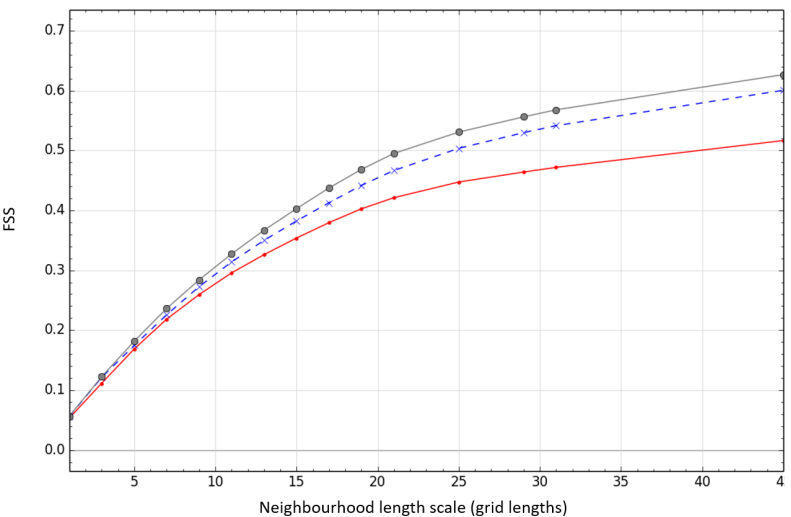

FIGURE 4. FSS with respect to GPM IMERG precipitation analyses for 24hourly accumulated precipitation threshold of $64 \mathrm{~mm}$ calculated over the full domain and averaged over the period 1 to 30 September 2013, for SINGV-DS with a forecast model horizontal resolution of $4.5 \mathrm{~km}$ (red), 2.2 $\mathrm{km}$ (blue) and $1.5 \mathrm{~km}$ (black). The neighborhood length scales are in multiples of $0.1^{\circ}$, which is the resolution of the GPM IMERG product.
Parallel experiments were carried out over a 1-month period in June 2011. The SINGV 1.0 outperformed WRF in most forecast scores. Example verification is shown in Figure 3 of FSS for the $24 \mathrm{~h}$ accumulated precipitation above $16 \mathrm{~mm}$ are shown as function of the scale. Comparing the WRF runs with UM_G (UM-WRF) and with GFS (GFS-WRF) as initial conditions and lateral boundary conditions, it is evident UM_G provides a better driving model (at least at that time). A second major result is the impact of regional model using the same (UM_G) LBCs: Figure 3 indicates a significant boost in FSS comparing UM-SINGV with UMWRF for the $16 \mathrm{~mm}$ rainfall threshold. These encouraging results ensured the further SINGV development and carried the project to the second year.

Figure 3 also indicates the impact of model resolution on FSS. Both high-resolution (1.5 km) GFS-WRF and UMWRF model runs have consistently better scores than the low-resolution $(4.5 \mathrm{~km})$ runs. However, for SINGV 1.0 the high-resolution results were worse than the low-resolution results. This was not expected and pushed the SINGV team to further revisions of the SINGV configuration during the second year of the project. It is noteworthy in Figure 3 that the impact of the regional model resolution (for SINGV and

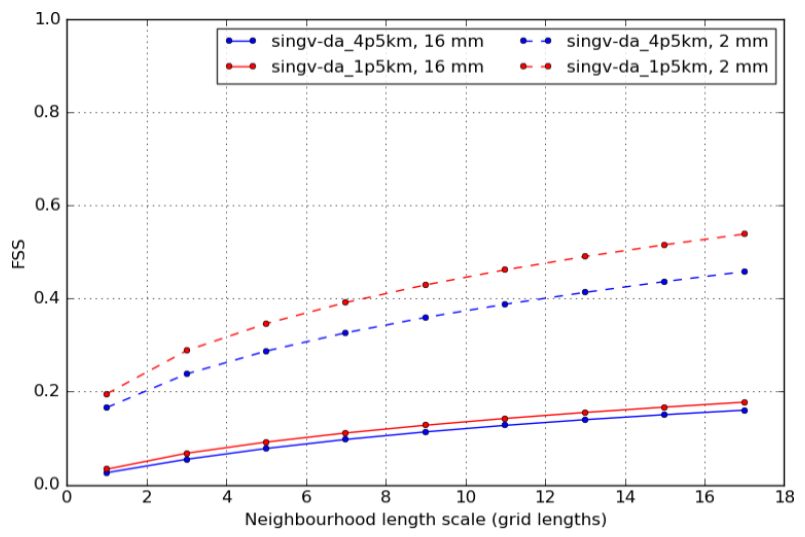

FIGURE 5. FSS with respect to GPM IMERG precipitation analyses for threehourly accumulated precipitation thresholds of $2 \mathrm{~mm}$ (dashed lines) and $16 \mathrm{~mm}$ (solid lines), valid at T+12, calculated over the full domain and averaged over all cycles in the period 2 to 14 May 2018, for SINGV-DA with a forecast model horizontal resolution of $4.5 \mathrm{~km}$ (blue) and $1.5 \mathrm{~km}$ (red) The neighborhood length scales are in multiples of $0.1^{\circ}$, which is the resolution of the GPM IMERG product.

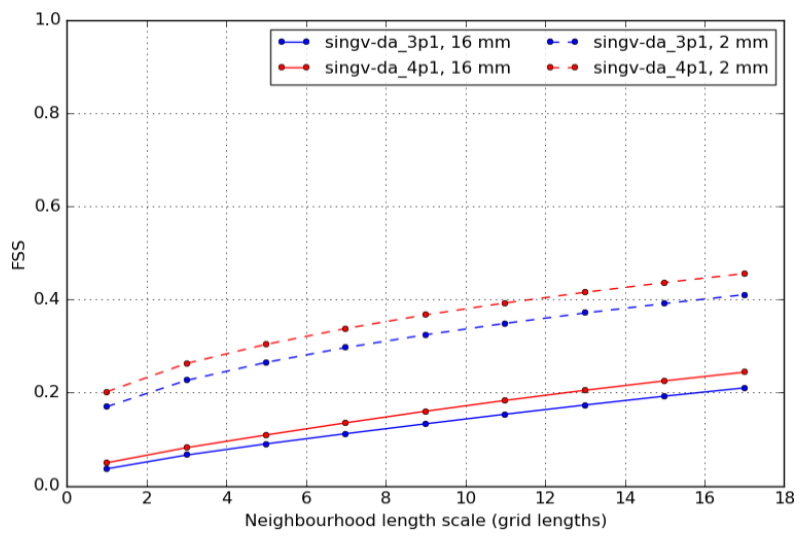

FIGURE 6. FSS with respect to GPM IMERG precipitation analyses for threehourly accumulated precipitation thresholds of $2 \mathrm{~mm}$ (dashed lines) and $16 \mathrm{~mm}$ (solid lines), valid at $\mathrm{T}+12$, calculated over the full domain and averaged over all data assimilation cycles in the period 2 to 24 November 2016, for experiments using Smith (blue) and PC2 (red). The neighborhood length scales are in multiples of $0.1^{\circ}$, which is the resolution of the GPM IMERG product. 


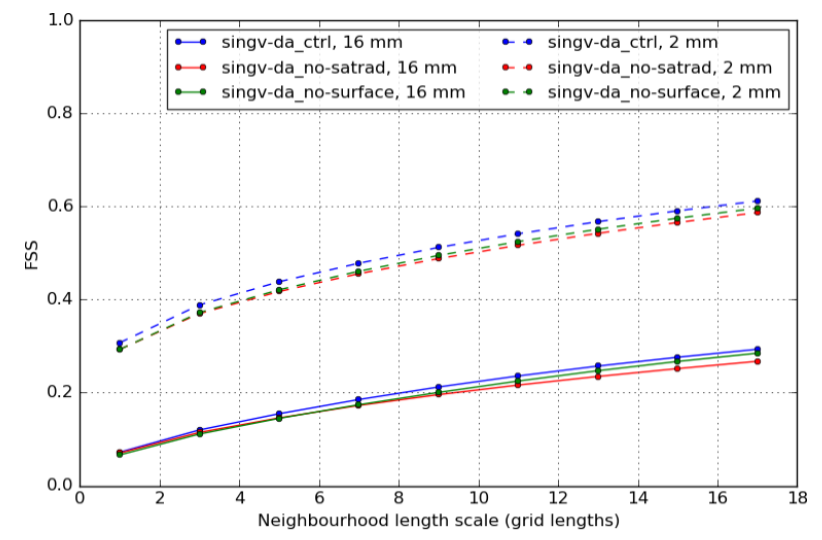

FIGURE 7. FSS with respect to GPM IMERG precipitation analyses for threehourly accumulated precipitation thresholds of $2 \mathrm{~mm}$ (dashed lines) and $16 \mathrm{~mm}$ (solid lines), valid at $\mathrm{T}+12$, calculated over the full domain and averaged over all cycles in the period 3 to 13 October 2018, for SINGVDA with all available observations assimilated (singv-da_ctrl; blue), with satellite radiances excluded (singv-da_no-satrad; red), and with surface observations excluded (singv-da_no-surface; green). The neighborhood length scales are in multiples of $0.1^{\circ}$, which is the resolution of the GPM IMERG product.

WRF) is considerably smaller than that seen by changing the global driving model or between the regional models used.

\subsection{Impact of resolution}

The final domain configuration, which was adopted for SINGV 2.0 and used for all subsequent versions, has only one domain (shown in Figure 1) using initial and lateral boundary conditions from a global NWP system (first UM_G, then ECMWF). With this configuration, the SINGV resolution impact indicated that $1.5 \mathrm{~km}$ is better than 2.2 $\mathrm{km}$, which is better than $4.5 \mathrm{~km}$, as shown in Figure 4 . The parallel runs were one month long over September 2013. Based on this comparison, we have used the $1.5 \mathrm{~km}$ domain configuration for SINGV-DS for the rest of the project and now for the pre-operational runs. The impact of model resolution was reassessed using later versions of the model and, recently, using the operational SINGV-DA system as described below.

The development of SINGV-DA was largely carried out with the forecast model resolution at $4.5 \mathrm{~km}$. A higher resolution of $1.5 \mathrm{~km}$ was later tested and chosen for the final operational configuration. The impact of this resolution change is shown in Figure 5. SINGV-DA's ability to resolve the small-scale convective structures prevalent in the deep tropics depends on the horizontal resolution of the forecast model. Accordingly, increasing the resolution from $4.5 \mathrm{~km}$ to $1.5 \mathrm{~km}$ resulted in improvements in precipitation forecast skill (Figure 5). The benefit is less apparent for larger rainfall thresholds, possibly because the convective cores of storm cells are, with respect to the evaluation grid, at the sub-grid scale.

\subsection{Impact of model physics}

The impact of model physics has been assessed each time that model changes are introduced to SINGV. As we mentioned in section 2, the blobbiness issue of the rainfall forecasts has been a key issue in SINGV development. The inclusion of a new, local moisture conservation scheme (Zerroukat and Shipway 2017) has led to an overall model improvement, although not much improvement was seen on the rainfall scores over the SINGV domain. Tuning the boundary layer scheme in SINGV has improved timing of rainfall initiation and peak intensity. The primary reason

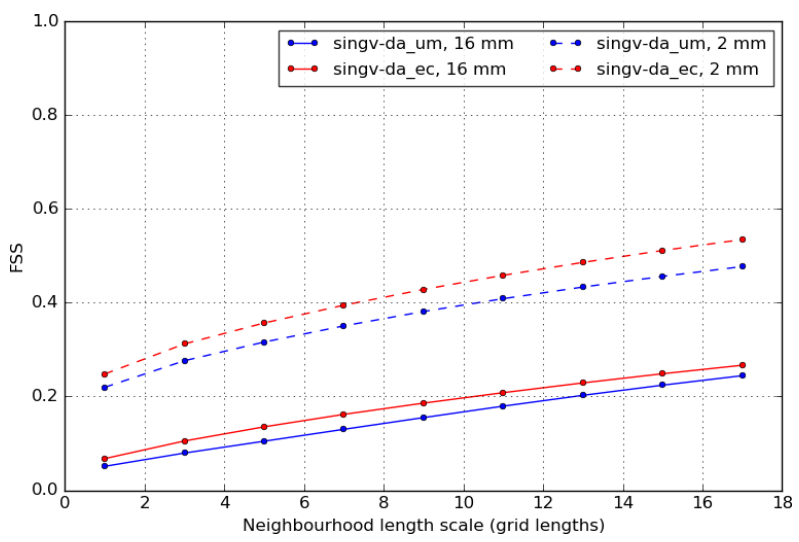

FIGURE 8. FSS with respect to GPM IMERG precipitation analyses for threehourly accumulated precipitation thresholds of $2 \mathrm{~mm}$ (dashed lines) and $16 \mathrm{~mm}$ (solid lines), valid at T+12, calculated over the full domain and averaged over all cycles in the period 6 to 18 September 2017, for SINGV-DA driven by UM_G (blue) and ECMWF (red) LBCs. The neighborhood length scales are in multiples of $0.1^{\circ}$, which is the resolution of the GPM IMERG product.

for this improvement is attributed to the deactivation of stochastic perturbation scheme as used in UKV. Use of the prognostic PC2 cloud scheme (Wilson et al. 2008) instead of the Smith diagnostic scheme (Smith 1990) resulted in a significant reduction of blobbiness in the rainfall forecasts, i.e., improved rainfall magnitude, distribution and organization. The relative dearth of squall lines in forecast using early SINGV versions was also alleviated to a certain degree by this change (Webster et al. 2020; Sun et al. 2020).

The sensitivity of SINGV forecasts to the cloud scheme formulation is reported in Webster et al. (2020) using SINGV-DS and in Heng et al. (2020) using the operational SINGV-DA. Figure 6 shows the impact of including the PC2 cloud scheme (Smith vs. PC2) on SINGV FSS. The PC2 clearly improved FSS across length scales and for different precipitation thresholds.

\subsection{Impact of observations}

Initial SINGV-DA efforts focused on the assimilation of conventional observations within the SINGV domain. Significant effort was then made on satellite radiances assimilation and variational bias correction of the data.

To evaluate the relative importance of each observation type assimilated into SINGV-DA, systematic observation impact assessments have been conducted. A set of observing system experiments (OSEs) have been performed over a 12-day period in October 2018, using the pre-operational SINGV-DA. The results indicate that satellite radiances and surface observations are more important relative to rawinsonde data, aircraft observations, atmospheric motion vectors and scatterometer surface wind observations. Figure 7 compares the precipitation FSS for the experiments without satellite radiances (no-satrad) and without surface observations (no-surface) with the corresponding numbers for the control run. It is confirmed that the assimilation of both satellite radiance and surface observations in SINGV leads to an improvement in SINGV precipitation forecast skill. The other OSEs are not represented in this plot because the impacts due to the other observations are much smaller than those shown here.

\subsection{Impact of the lateral boundary conditions}

The skill of regional NWP (both SINGV-DS and SINGV-DA) is expected to depend crucially on the accuracy of driving 


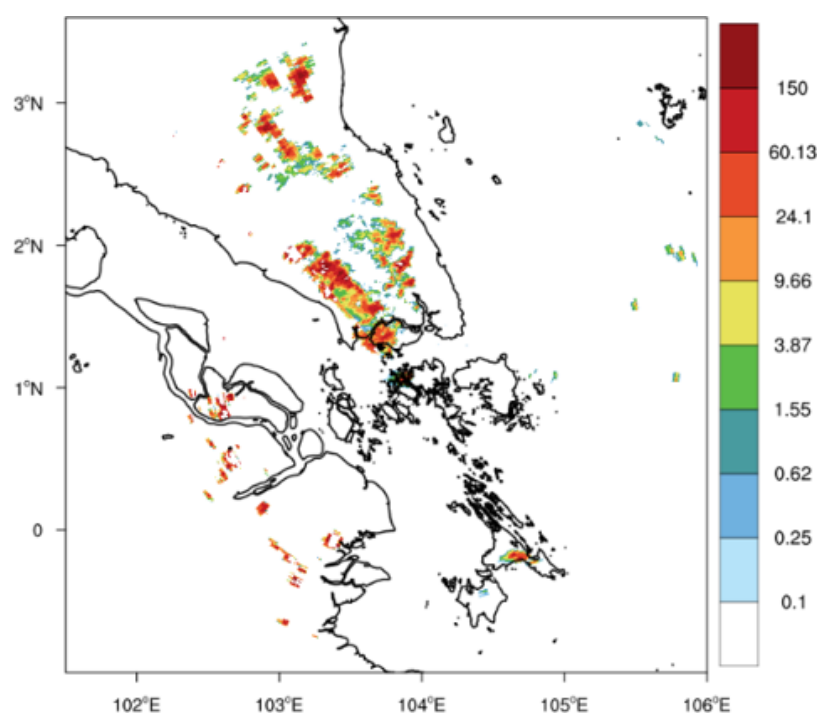

(a)

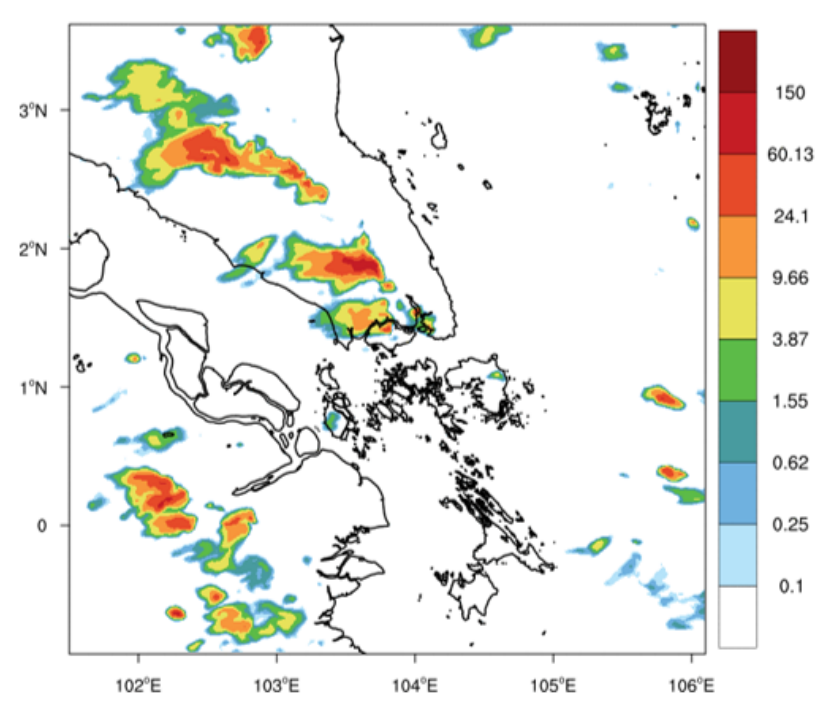

(b)

FIGURE 9. a) The heavy precipitation event on 10 November 2018 , as captured by the weather radar. b) The $\mathrm{T}+22 \mathrm{~h}$ forecast from the 12 UTC cycle of SINGV-DA on 9 November 2018.

model providing lateral (and initial, in the case of downscaler) boundary conditions. Initial results in SINGV indicated that using ECMWF's HRES forecasts, instead of the Met Office's global UM_G forecasts, resulted in significant improvements in the FSS of both SINGV-DS and SINGVDA precipitation forecasts. This impact has been reconfirmed with SINGV-DA over a 12-day period, as shown in Figure 8. The use of ECMWF HRES data as lateral boundary conditions leads to a significant increase in precipitation FSS across all spatial scales and for different precipitation thresholds. One of the plausible reasons for the relatively poor performance of global UM driven SINGV is the low influx of moisture from the lateral boundaries, which leads to less precipitation in the model when compared to GPM (see Webster et al. (2020) for details).

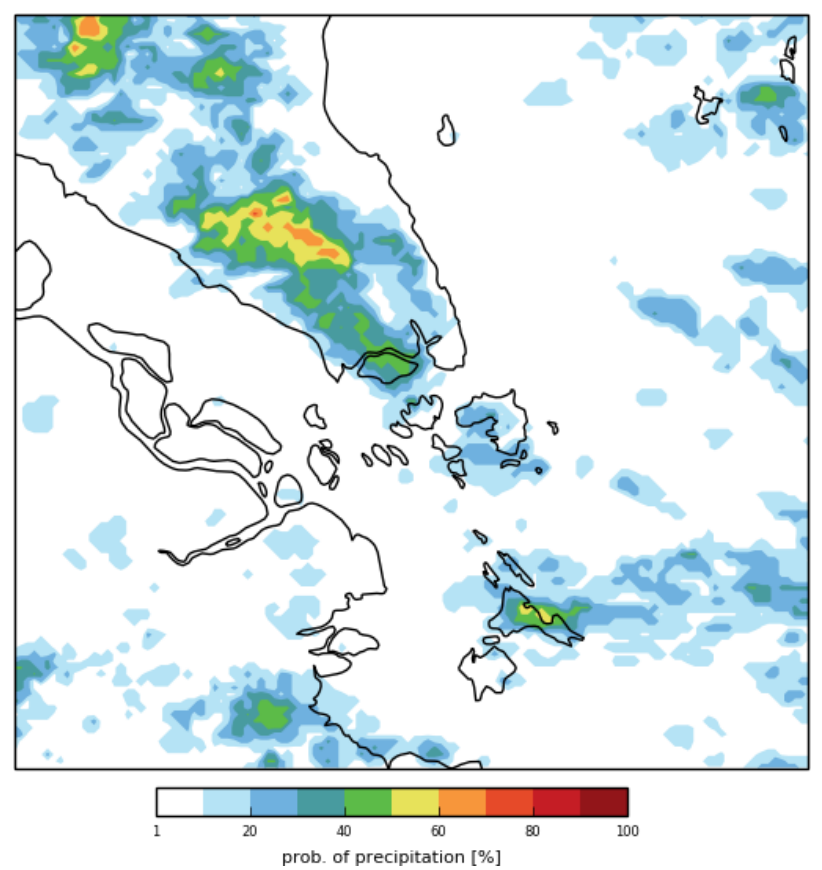

FIGURE 10. The T+22 forecast of the probability of precipitation above 0.1 $\mathrm{mm} / \mathrm{h}$ at 10 UTC on 10 November 2018, based on the 12 UTC, 9 November 2018 run of the 12-member SINGV-EPS.

\subsection{Ensemble predictions}

The current status of SINGV is illustrated by some forecast products issued by MSS on 10 November 2018. A heavy rain event occurred in the afternoon causing flooding in Singapore(Figure9a). The deterministicforecastfor this eventwas reasonably good with rainfall intensity and timing(Figure 9b).

The 12-member SINGV-EPS also indicated elevated probabilities of precipitation over Singapore at that time (Figure 10). A meteogram of hourly precipitation over Singapore based on the ensemble shows rainfall intensity peaking at the same time (Figure 11). Thus, taken as a whole, SINGV-EPS captured this event very well.

On the other hand, half of the 12 ensemble membersincluding the control-showed no rain over Singapore at all (Figure 12). This implies that the deterministic model could easily have missed this event with just a slightly different set of initial conditions. This underscores the need for a probabilistic approach to capture such events and to quantify the associated uncertainties.

\section{CONCLUSIONS}

Challenges in convective-scale NWP, especially over the deep tropics, have been long known to the research community. Efforts have been taken internationally to push forward research in this direction. To join this effort, MSS and UKMO started a collaborative project in 2013 to develop a convective-scale NWP system, SINGV, at MSS with a focus

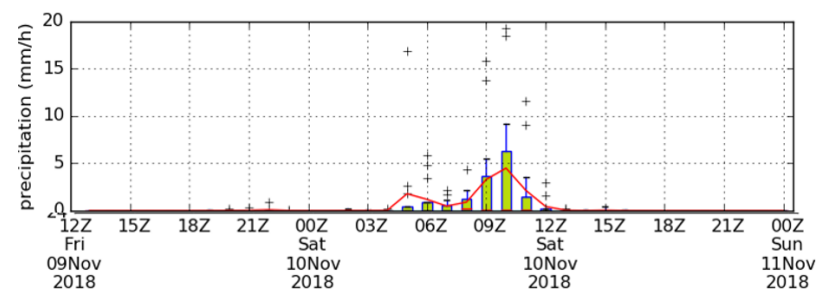

FIGURE 11. Meteogram of the hourly precipitation within a $5 \times 5$ box centered on Singapore $\left(103.8^{\circ} \mathrm{E}, 1.4^{\circ} \mathrm{N}\right)$ derived from SINGV-EPS. Each box spans the interquartile range (IQR) of the forecast precipitation from the ensemble members. The whisker extends to 1.5 times the IQR, and any forecast beyond that is marked with a cross. The ensemble mean is shown as the red line. 


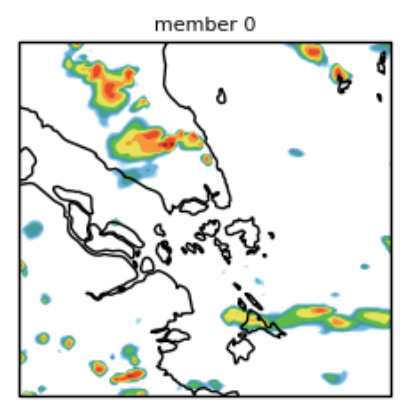

member 7

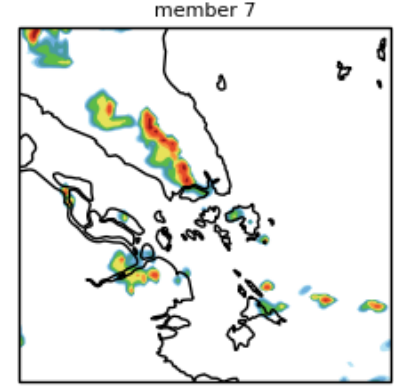

member 15

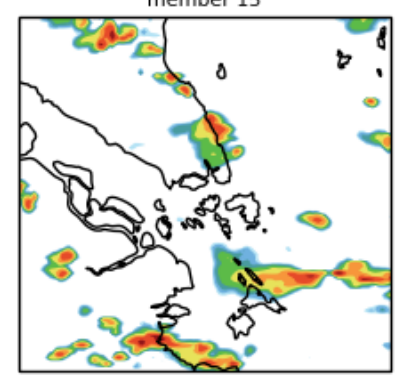

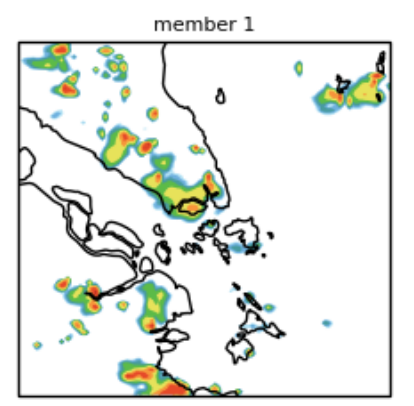

member 9

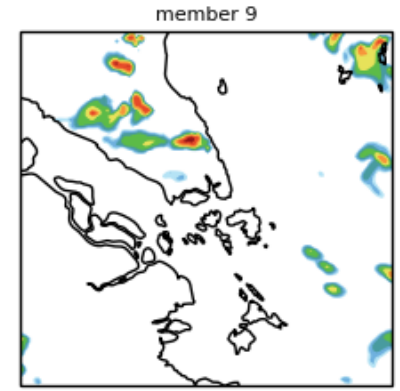

member 17

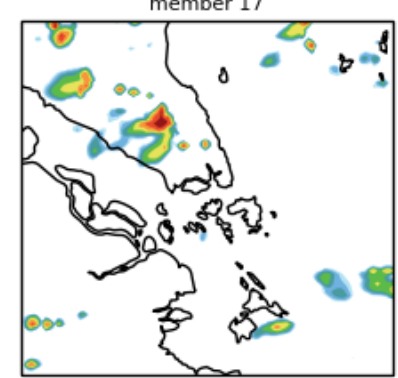

member 3

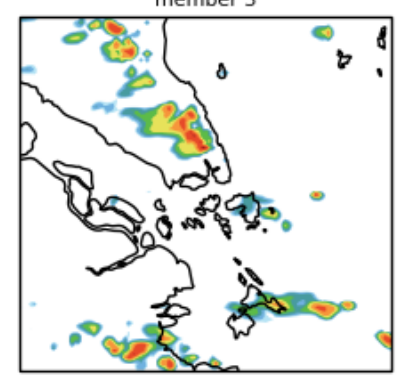

member 11

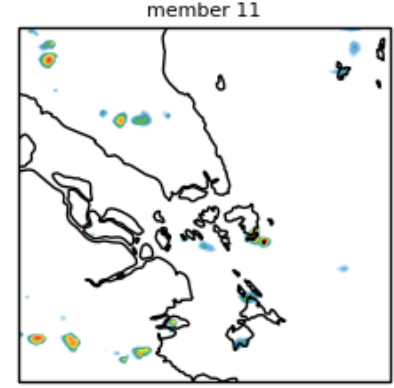

member 19

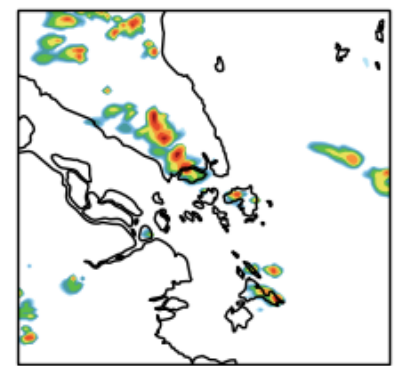

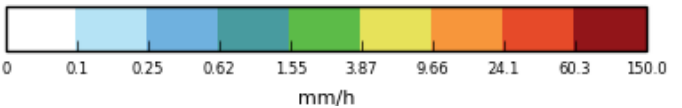

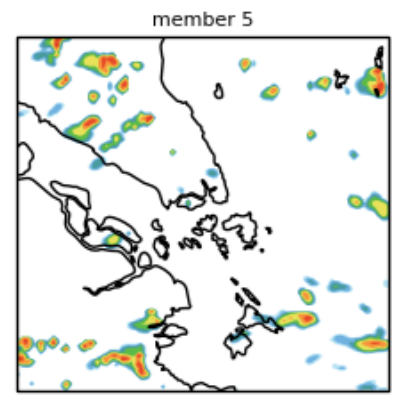

member 13

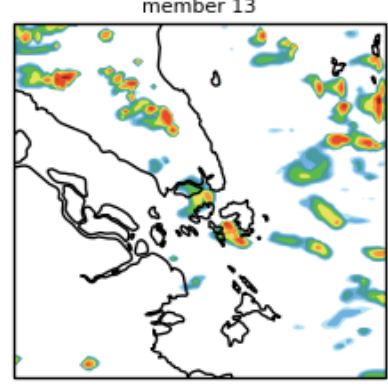

member 21

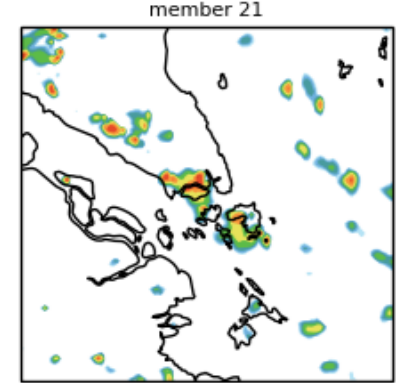

FIGURE 12. Precipitation forecasts (T+22) from all 12 members of the SINGV-EPS valid at 10 UTC on 10 November 2018.

on improved forecast quality for localized thunderstorms for Singapore and surrounding region.

Over the past six years, the convective-scale NWP capabilities of MSS have taken a step forward with the implementation of a km-scale UM-based deterministic/ensemble system, assimilating data from a wide range of surface- and space-based platforms. Initial limitations of the system e.g. rainfall biases and 'blobby' convective systems have been resolved through improved physics and modelling techniques. Some of these (e.g. moisture conservation) have led to improvements in other implementation of the regional UM (e.g. UKV). Furthermore, our results have shown ECMWF driven SINGV to provide improved forecast skill over UM global driven SINGV, which highlights the importance of driving model on regional NWP. Impact of the regional model on forecast skill has also been demonstrated by comparing UM global driven SINGV and WRF. Although WRF has more exposure to tropical convective-scale applications, for the trials conducted during the project, SINGV was found to be superior than WRF in most forecast scores.

In addition to the development of capabilities at MSS, this project has also highlighted the value of collaborative research which led to bug fixes, science improvements, and varied evaluation of a system that is used worldwide among various UM science partners. It is to be noted that SINGV forms the starting point of the tropical science configura- tion (Bush et al. 2019), which is now accessible to all the UM science partners for testing and evaluation.

Although SINGV has been in operation since July 2019, further research and development have been ongoing and planned. For data assimilation, we aim to implement a hybrid ensemble-variational data assimilation system following Clayton et al. (2013) and hourly 4D-Var following Ballard et al. (2016). For ensemble prediction, SINGV-EPS will be further developed to have ensemble perturbations centered around the analyses produced by SINGV-DA, following the current MOGREPS-UK (Hagelin et al. 2017). Configurations with higher model resolutions and more ensemble members will also be assessed.

While SINGV has been the key modelling system for convective-scale NWP activities at MSS we have also worked on using SINGV as an urban model to study the urban impact on weather and climate (Simón-Moral et al. 2019) and on coupling SINGV with an ocean model to study the air-sea interaction and its impact on forecasts (Thompson et al. 2019). Work also started to develop SINGV as a regional climate model to be used in the next Singapore national climate change projection in 2022 (Timbal et al. 2019).

\section{GLOSSARY}

3D-Var Three-dimensional variational data assimilation. 4D-Var Four-dimensional variational data assimilation. 
DA Data Assimilation.

DS Downscaler.

ECMWF European Centre for Medium-Range Weather Forecasts.

EPS Ensemble Prediction System.

FSS Fractions Skill Score.

GFS Global Forecast System.

GPM Global Precipitation Measurement.

GTS Global Telecommunication System.

HRES ECMWF's global high-resolution deterministic forecast system.

IMERG Integrated Multi-Satellite Retrievals for GPM.

LBC Lateral Boundary Conditions.

MSS Meteorological Service Singapore.

NWP Numerical Weather Prediction.

OSE Observing System Experiment.

PC2 Prognostic cloud fraction and prognostic condensate scheme.

SINGV Limited area configuration of the Unified Model for Singapore.

SMC Soil Moisture Content.

SST Sea Surface Temperature.

UKMO United Kingdom Met Office.

UKV Variable-resolution limited area configuration of the Unified Model for the United Kingdom.

UM Unified Model.

WRF Weather Research and Forecasting.

\section{REFERENCES}

Aranami K, Davies T, Wood N. 2015. A mass restoration scheme for limited-area models with semi-Lagrangian advection. Quart J Roy Meteor Soc. 141(690):1795-1803. doi:10.1002/qj.2482.

Ballard SP, Li Z, Simonin D, Caron JF. 2016. Performance of 4D-Var NWP-based nowcasting of precipitation at the Met Office for summer 2012: 4D-Var NWP-based Nowcasting of precipitation. Quart J Roy Meteor Soc. 142(694):472-487. doi:10.1002/qj.2665.

Bannister RN. 2017. A review of operational methods of variational and ensemble-variational data assimilation. Quart J Roy Meteor Soc. 143(703):607-633. doi:10.100 2/qj.2982.

Best MJ, Pryor M, Clark DB, Rooney GG, Essery RLH, Ménard CB, Edwards JM, Hendry MA, Porson A, Gedney N, et al. 2011. The Joint UK Land Environment Simulator (JULES), model description - part 1: energy and water fluxes. Geosci Model Dev. 4(3):677-699. doi: 10.5194/gmd-4-677-2011.

Bloom SC, Takacs LL, da Silva AM, Ledvina D. 1996. Data assimilation using incremental analysis updates. Mon Weather Rev. 124(6):1256-1271. doi:10.1175/1520-049 3(1996)124<1256:DAUIAU> 2.0.CO;2.

Boutle IA, Eyre JEJ, Lock AP. 2014. Seamless stratocumulus simulation across the turbulent gray zone. Mon Weather Rev. 142(4):1655-1668. doi:10.1175/MWR-D13-00229.1.

Bowler NE, Arribas A, Mylne KR, Robertson KB, Beare SE. 2008. The MOGREPS short-range ensemble prediction system. Quart J Roy Meteor Soc. 134(632):703-722. doi: 10.1002/qj.234.

Brown A, Milton S, Cullen M, Golding B, Mitchell J, Shelly A. 2012. Unified modeling and prediction of weather and climate: a 25-year journey. Bull Amer Meteor Soc. 93(12):1865-1877. doi:10.1175/BAMS-D-12-00018.1.

Brown AR. 1999. The sensitivity of large-eddy simulations of shallow cumulus convection to resolution and subgrid model. Quart J Roy Meteor Soc. 125(554):469-482. doi: 10.1002/qj.49712555405.

Bush M, Allen T, Bain C, Boutle I, Edwards J, Finnenkoetter A, Franklin C, Hanley K, Lean H, Lock A, et al. 2019. The first Met Office Unified Model/JULES Regional Atmosphere and Land configuration, RAL1. Geosci Model Dev Discuss, in review. doi:10.5194/gmd-2019-130.

Cameron J, Bell W. 2015. Pre-operational testing of variational bias correction (VarBC). Satellite Applications Technical Memo 37. Exeter: Met Office.

Clayton AM, Lorenc AC, Barker DM. 2013. Operational implementation of a hybrid ensemble/4D-Var global data assimilation system at the Met Office. Quart J Roy Meteor Soc. 139(675):1445-1461. doi:10.1002/qj.2054.

Donlon CJ, Martin M, Stark J, Roberts-Jones J, Fiedler E, Wimmer W. 2012. The Operational Sea Surface Temperature and Sea Ice Analysis (OSTIA) system. Remote Sens Environ. 116:140-158. doi:10.1016/j.rse.2010.10.017.

Edwards J, Slingo A. 1996. Studies with a flexible new radiation code. i: choosing a configuration for a largescale model. Quart J Roy Meteor Soc. 122(531):689-719. doi:10.1002/qj.49712253107.

Gustafsson N, Janjić T, Schraff C, Leuenberger D, Weissmann M, Reich H, Brousseau P, Montmerle T, Wattrelot E, Bučánek A, et al. 2018. Survey of data assimilation methods for convective-scale numerical weather prediction at operational centres. Quart J Roy Meteor Soc. 144(713):1218-1256. doi:10.1002/qj.3179.

Hagelin S, Son J, Swinbank R, McCabe A, Roberts N, Tennant W. 2017. The Met Office convective-scale ensemble, MOGREPS-UK. Quart J Roy Meteor Soc. 143(708):28462861. doi:10.1002/qj.3135.

Heng BCP, Tubbs R, Huang XY, Macpherson B, Barker DM, Boyd DFA, Kelly G, North R, Stewart L, Webster S. 2020. SINGV-DA: A data assimilation system for convectivescale numerical weather prediction over Singapore. Quart J Roy Meteorol Soc, in review.

Hough MN, Jones RJA. 1997. The United Kingdom Meteorological Office rainfall and evaporation calculation system: MORECS version 2.0-an overview. Hydrol Earth Syst Sci. 1(2):227-239. doi:10.5194/hess-1-227-1997.

Ingleby NB. 2001. The statistical structure of forecast errors and its representation in the Met. Office Global 3-D Variational Data Assimilation Scheme. Quart J Roy Meteor Soc. 127(571):209-231. doi:10.1002/qj.49712757112.

Lilly DK. 1962. On the numerical simulation of buoyant convection. Tellus. 14(2):148-172. doi:10.3402/tellusa.v14i2. 9537.

Lock AP, Brown AR, Bush MR, Martin GM, Smith RNB. 2000. A new boundary layer mixing scheme. Part I: scheme description and single-column model tests. Mon Weather Rev. 128(9):3187-3199. doi:10.1175/1520-0 493(2000)128<3187:ANBLMS > 2.0.CO;2.

Lorenc AC, Ballard SP, Bell RS, Ingleby NB, Andrews PLF, Barker DM, Bray JR, Clayton AM, Dalby T, Li D, Payne TJ, Saunders FW. 2000. The Met. Office global three-dimensional variational data assimilation scheme. Quart J Roy Meteor Soc. 126(570):2991-3012. doi:10.1002/qj.49712657002.

Molteni F, Buizza R, Palmer TN, Petroliagis T. 1996. The ECMWF Ensemble Prediction System: methodology and validation. Quart J Roy Meteor Soc. 122(529):73-119. doi:10.1002/qj.49712252905.

Morcrette CJ. 2012a. Improvements to a prognostic cloud scheme through changes to its cloud erosion 
parametrization. Atmos Sci Lett. 13(2):95-102. doi: 10.1002/asl.374.

Morcrette CJ. 2012b. Prognostic-cloud-scheme increment diagnostics: a novel addition to the case-study tool kit. Atmos Sci Lett. 13(3):200-207. doi:10.1002/asl.380.

Porson AN, Hagelin S, Boyd DFA, Roberts NM, North R, Webster S, Lo JCF. 2019. Extreme rainfall sensitivity in convective-scale ensemble modelling over Singapore. Quart J Roy Meteorol Soc. 145:3004-3022. doi:10.100 2/qj.3601.

Rawlins F, Ballard SP, Bovis KJ, Clayton AM, Li D, Inverarity GW, Lorenc AC, Payne TJ. 2007. The Met Office global four-dimensional variational data assimilation scheme. Quart J Roy Meteor Soc. 133(623):347-362. doi:10.1002/ qj.32.

Renshaw R, Francis PN. 2011. Variational assimilation of cloud fraction in the operational Met Office Unified Model. Quart J Roy Meteorol Soc. 137:1963-1974. doi: 10.1002/qj.980.

Roberts NM, Lean HW. 2008. Scale-selective verification of rainfall accumulations from high-resolution forecasts of convective events. Mon Weather Rev. 136(1):78-97. doi:10.1175/2007MWR2123.1.

Simón-Moral A, Dipankar A, Roth M, Sánchez C, Velasco E, Huang XY. 2019. Application of a single layer urban canopy model in a tropical city: preliminary results from Singapore. Quart J Roy Meteorol Soc. doi: 10.1002/qj.3694.

Skamarock WC, Klemp JB, Dudhia J, Gill DO, Barker DM, Duda M, Huang XY, Wang W, Powers JG. 2008. A description of the advanced research WRF version 3 . Technical report. UCAR/NCAR. doi:10.5065/D68S4M $\mathrm{VH}$.

Skofronick-Jackson G, Petersen WA, Berg W, Kidd C, Stocker EF, Kirschbaum DB, Kakar R, Braun SA, Huffman GJ, Iguchi T, et al. 2017. The Global Precipitation Measurement (GPM) mission for science and society. Bull Amer Meteor Soc. 98(8):1679-1695. doi: 10.1175/BAMS-D-15-00306.1.

Smith RNB. 1990. A scheme for predicting layer clouds and their water content in a general circulation model. Quart J Roy Meteor Soc. 116(492):435-460. doi:10.1002/ qj.49711649210.

Sun X, Huang XY, Gordon C, Mittermaier M, Beckett R, Cheong WK, Barker DM, North R, Semple A. 2020. A subjective and objective evaluation of model forecasts of Sumatra squall events. Weather and Forecasting, in review.

Tang Y, Lean HW, Bornemann J. 2013. The benefits of the Met Office variable resolution NWP model for forecasting convection: variable resolution NWP for forecast- ing convection. Meteorol Appl. 20(4):417-426. doi: 10.1002/met.1300.

Thompson B, Sanchez C, Sun X, Song G, Liu J, Huang XY, Tkalich P. 2019. A high-resolution atmosphere-ocean coupled model for the western Maritime Continent: development and preliminary assessment. Climate Dyn. 52(7-8):3951-3981. doi:10.1007/s00382-018-4367-0.

Timbal B, Venkatraman P, Hassim M. 2019. SINGV as a Regional Climate Model to deliver Singapore's 3rd National Climate Change Study. MSS Res Lett. 2(4):3-13.

Walters D, Baran AJ, Boutle I, Brooks M, Earnshaw P, Edwards J, Furtado K, Hill P, Lock A, Manners J, et al. 2019. The Met Office Unified Model Global Atmosphere 7.0/7.1 and JULES Global Land 7.0 configurations. Geosci Model Dev. 12(5):1909-1963. doi:10.519 4/gmd-12-1909-2019.

Webster S, Dipankar A, Furtado K, Wilkinson J, Sanchez C, Lock A, North R, Sun X, Vosper S, Huang XY, Barker DM. 2020. SINGV: a convective-scale weather forecast model for Singapore. Quart J Roy Meteorol Soc, to be submitted.

Wilson DR, Ballard SP. 1999. A microphysically based precipitation scheme for the UK Meteorological Office Unified Model. Quart J Roy Meteor Soc. 125(557):1607-1636. doi:10.1256/smsqj.55706.

Wilson DR, Bushell AC, Kerr-Munslow AM, Price JD, Morcrette CJ. 2008. PC2: a prognostic cloud fraction and condensation scheme. I: scheme description. Quart J Roy Meteor Soc. 134(637):2093-2107. doi:10.1002/qj.3 33.

Wood N, Staniforth A, White A, Allen T, Diamantakis M, Gross M, Melvin T, Smith C, Vosper S, Zerroukat M, Thuburn J. 2014. An inherently mass-conserving semiimplicit semi-Lagrangian discretization of the deepatmosphere global non-hydrostatic equations. Quart J Roy Meteor Soc. 140(682):1505-1520. doi:10.1002/qj.2 235.

Zerroukat M. 2010. A simple mass conserving semiLagrangian scheme for transport problems. J Comput Phys. 229(24):9011-9019. doi:10.1016/j.jcp.2010.08.017.

Zerroukat M, Shipway BJ. 2017. ZLF (Zero Lateral Flux): a simple mass conservation method for semiLagrangian-based limited-area models: conservation in Limited Area Models. Quart J Roy Meteor Soc. 143(707):2578-2584. doi:10.1002/qj.3108.

Žagar N, Isaksen L, Tan D, Tribbia J. 2013. Balance properties of the short-range forecast errors in the ECMWF 4D-Var ensemble. Quart J Roy Meteor Soc. 139(674):1229-1238. doi:10.1002/qj.2033. 